OAI-PMH: http://www.indteca.com/ojs/index.php/Revista Scientific/oai

Artículo Original / Original Article

\title{
La pedagogía biocéntrica: del currículum disciplinario-normativo al reencantamiento de la educación
}

\author{
Autora: Claudia Liliana Perlo Pachega \\ Instituto Rosario de Investigaciones en Ciencias de la Educación, IRICE (CONICET / UNR) \\ perlo@irice-conicet.gov.ar \\ Santa Fe, Argentina \\ https://orcid.org/0000-0002-9363-3952
}

\section{Resumen}

En este trabajo realizamos una revisión teórica profunda del currículum que aún opera oculto en las prácticas educativas cotidianas, escolares y no escolares. Ponemos especial énfasis en estas últimas, reconociendo la potente fuerza educadora de la acción social. En el desarrollo del mismo abordamos la normalidad como patología, la represión de los instintos como germen de la violencia escolar y social hoy vigente y el lugar del cuerpo en el modelo normativo-disciplinario que moldeó una educación racional, patriarcal y antropocéntrica. Proponemos transitar hacia una perspectiva biocéntrica de la educación que posibilite el reencantamiento del currículum. Para ello presentamos una pedagogía basada en el principio biocéntrico, poniendo énfasis en la recuperación de los instintos, en la vivencia como fuente de conocimiento y la vida como eje del currículum. El trabajo culmina con apreciaciones que invitan a reencantar el currículum a través de la mirada que reconoce, califica y hospeda a la otredad.

Palabras clave: evaluación del currículo; educación; disciplina escolar.

Fecha de Recepción: 11-12-2018

Fecha de Aceptación: 29-03-2019 


\title{
The biocentric pedagogy: from the disciplinary-normative curriculum to the re-enchantment of education
}

\begin{abstract}
In this work we carry out a deep theoretical revision of the curriculum that still operates hidden in everyday educational practices, school and nonschool. We put special emphasis on the latter, recognizing the powerful educative force of social action. In the development of the same address normality as a pathology, the repression of instincts as the germ of school and social violence today and the place of the body in the normative-disciplinary model that shaped a rational education, patriarchal and anthropocentric. We propose to move towards a biocentric perspective of education that makes possible the re-enchantment of the curriculum. For this we present a pedagogy based on the biocentric principle, emphasizing the recovery of the instincts, the experience as a source of knowledge and life as the core of the curriculum. The work culminates with appreciations that invite to re-enchant the curriculum through the look that recognizes, qualifies and hosts the otherness.
\end{abstract}

Keywords: curriculum evaluation; education; school discipline.

Date Received: $11-12-2018$

Date Acceptance: 29-03-2019 


\section{Introducción}

El corpus teórico que aquí presentamos, constituye una revisión sistemática sobre el tema, enmarcada en lo que Strauss y Corbin (1994): denominan Grounded Theory (pág. 66). Esto significa que dicha teoría se ha gestado en el trabajo de campo de nuestras investigaciones que llevamos a cabo en el contexto organizativo; donde hemos puesto en juego las categorías que aquí desarrollamos.

Teniendo en cuenta la necesidad en la que se encuentran los profesores debido a que cada alumno posee según López (2019): "un cúmulo de sentimientos, emociones, pensamientos y situaciones que debe vivir que son en gran parte barreras para su formación" (pág. 69); este trabajo está dirigido a docentes en los diferentes roles que puedan desempeñar en los contextos educativos.

Ofrecemos un abordaje biocéntrico de la educación para provocar una reflexión profunda, a la medida de los cambios radicales que requieren nuestros actuales sistemas escolares. Este enfoque pone en cuestión la educación normativa y disciplinaria aún vigente en el sistema educativo y al mismo tiempo ofrece nuevas perspectivas para sustentar una educación potenciadora del ser y del ser con otros.

En primer lugar, realizamos una revisión del currículum. Entendido este último, más allá de los programas escolares. Se trata de un proyecto pedagógico amplio y complejo, que involucra una concepción del ser, de la realidad y la naturaleza del encuentro humano. Ponemos especial énfasis en estas últimas ya que quizás la mayor potencia de la educación no esté en la escuela, sino en la fuerza educadora que produce la sola acción social.

Desde esta perspectiva curricular abordamos la normalidad como una patología y la represión de los instintos como germen de la violencia hoy vigente. Asimismo, referimos al lugar del cuerpo en el modelo normativodisciplinario, que moldeó una educación racional, patriarcal y antropocéntrica. 
Seguidamente proponemos transitar hacia una perspectiva biocéntrica de la educación que posibilite el reencantamiento del currículum. Para ello proponemos una pedagogía basada en los conceptos de Rolando Toro Araneda, quien pone énfasis en la recuperación de los instintos, en la vivencia como fuente de conocimiento y la vida como eje del currículum.

El trabajo culmina con apreciaciones finales que invitan a despegarse definitivamente de la mirada sancionadora, para reencontrarnos con la mirada que reconoce, califica y hospeda a la otredad.

\section{Desarrollo}

\subsection{Hacia la revisión del currículum disciplinario}

\subsubsection{La normalidad como patología}

Para comenzar con este punto referiremos a la siguiente frase de Foster (2010):

La normalidad jamás podrá contener la inmensidad de tu corazón. Cada ola en el océano es única, no es ni normal ni anormal, sino una expresión del océano mismo. El océano permite todas sus olas, porque es todas sus olas (pág. 33).

Tradicionalmente se ha tratado como a-normal a lo diferente, lo irregular, lo que falta o lo que sobra dentro de un molde o matriz que define lo que es normal. Dentro del ámbito de las ciencias sociales, donde nos interesa centrar esta discusión, Comte (1830); y Durkheim (1985): son los referentes principales de la filosofía y sociología respectivamente que abordan profundamente esta cuestión. Posteriormente es Canguilhem (1990a): quien realiza un fundamental aporte desde la filosofía francesa (pág. 27). En su obra "Lo normal y lo patológico" el autor Canguilhem (1990b): deja en claro "la naturaleza dogmática de la concepción epistemológica que diferencia salud de enfermedad" (pág. 97); retoma concepciones antiguas que entienden a la 
enfermedad como perturbación del equilibrio que guarda el organismo en relación a la naturaleza. Asimismo, la enfermedad no es solamente desequilibrio o desarmonía, es también esfuerzo de la naturaleza en el hombre, para obtener un nuevo equilibrio.

El desarrollo teórico de este concepto ha sido extenso y prolífero y hoy podemos afirmar que la normalidad se erige sobre una base compleja de múltiples factores históricos, políticos y culturales. De este modo Carpintero (2015a), define: "un hombre promedio o un niño promedio" con relación a las características más próximas a la media aritmética del grupo a que pertenece" (pág. 92). A partir de esta base, será normal todo sujeto que se aproxime al modelo esperable y deseable. De igual forma, Carpintero (2015b), refiere que: "el disciplinamiento se ha interiorizado en la búsqueda de una normalidad cuyo efecto es la emergencia de la pulsión de muerte: la violencia destructiva y autodestructiva, la sensación de vacío, la nada" (pág. 51). Es en este sentido que sostenemos que la normalización y el disciplinamiento presentan una cuestión bien delicada, si consideramos que el derecho de cada cual, no debía ser otra cosa que la potencia que tiene para existir y actuar.

\subsubsection{La represión de los instintos}

Para el psicoanalista, Reich (1927a), sostiene que: "las perturbaciones psíquicas son el resultado del caos sexual originado por las características de la sociedad opresora" (pág. 88); dicho caos, somete a los individuos con el objetivo de reprimir psíquicamente a las personas que, educadas en la negación de la vida, quedan confinadas a la angustia de placer. Las personas que viven natural y libremente su sexualidad difícilmente puedan ser sometidas y disciplinadas. Según Reich (1927b), la negación de la sexualidad: "Es la base del miedo a una vida libre e independiente" (pág. 127).

La cultura patriarcal y autoritaria produce en el hombre moderno un acorazamiento en contra de su propia naturaleza, que lo deja enajenado en el 
sí mismo. Estos movimientos acorazados son producto y además recursivamente reproductores de sentimientos inconscientes de culpa, miedo al castigo, a la excitación placentera. Han generado una moralidad y política basada en el sometimiento a la autoridad, la obediencia y la hipocresía normativa. En este contexto, el sistema educativo para el autor Naranjo (2010a): "se vuelve un espacio reproductor del orden social imperante" (pág. 27). Un curriculum orientado a la normalidad des potencia y solo genera más de lo mismo, en una sociedad humana devastada de tanta represión.

\subsubsection{El lugar del cuerpo en el modelo normativo-disciplinario}

El abordaje de esta cuestión encuentra un indiscutible referente, Foucault (1975a): quien puso en relación el concepto de poder con el control total de los cuerpos vivos (pág. 48). La educación en general y la escuela en particular, agrega el autor, Foucault (1975b): "han sido entendidos como ámbitos de disciplinamiento" (pág. 19); cuya función ha sido según Althusser (1970): "controlar, dominar y castigar en tanto aparatos ideológicos del estado" (pág. 20).

Este disciplinamiento que se encarnó en los cuerpos, constituyó el eje de un currículum basado en la normalidad, la represión, el sometimiento y la obediencia. El sistema educativo ha organizado detalladamente el tiempo y el espacio escolar para forjar cuerpos exteriormente enyesados e interiormente dóciles. La disposición espacial en las aulas, de banco amurados y en línea desvanecieron la presencia plena de sí misma y del otro.

El filósofo Foucault (1975c), expresa: el cuerpo es útil cuando es productivo y sometido, estos sometimientos no se obtienen solo por la violencia (pág. 101). El sometimiento adquiere su mayor efectividad cuando existe una organización externa del cuerpo: cómo, cuándo y dónde pararse, cómo, cuándo y cómo sentarse, hacia qué dirección mirar y a quién.

De este modo las organizaciones, en especial las educativas que son 
de nuestro interés aquí, ya que instauraron en el aula como menciona Foucault (1975d): tecnología política del cuerpo (pág. 42). Al igual que se fabrica el cuerpo de un soldado, el cual puede reconocerse según Foucault en su marcha vigorosa, gesto grave y caminar altivo, cabeza alta y derecha, se fabrica con disciplinamiento el cuerpo de un alumno. La docilidad to vuelve más hábil a las respuestas que se espera de él. Nos encontramos ante una reducción materialista del ser y una teoría general de la educación, donde domina la noción de docilidad que une al cuerpo analizable con el cuerpo manipulable. Sobre ese cuerpo analizable se erige la disciplina, como un tipo de poder, una anatomía política que fundará las bases del currículum.

\subsubsection{El Modelo disciplinario como fundamento del currículum}

Tomamos las palabras de Foucault (1975e), cuando dice que: "a estos métodos que permiten el control minucioso de las operaciones del cuerpo, que garantizan la sujeción constante de sus fuerzas, y les imponen una relación de docilidad-utilidad, es a lo que se puede llamar las disciplinas" (pág. 89).

Sobre las bases del modelo disciplinario se fundó el curriculum escolar, el cual encontró un fuerte anclaje en la construcción del estado moderno, al que recursivamente le dio sustento. Entendemos este modelo disciplinario en su doble acepción, la que Foucault ha analizado en términos de docilidadutilidad y la que íntimamente emparentada con ésta, refiere a la organizaciónorden del conocimiento, plasmado en el currículum.

La modernidad y el positivismo se abocaron a organizar, ordenar y clasificar lo normal y lo anormal en el mundo físico, natural y social. Este modo de comprensión fue delineando un universo-máquina en el cual podrían predecirse y controlarse todos los fenómenos a través de leyes y ecuaciones matemáticas que permitan predecir su funcionamiento y comportamiento; todo lo que podía observarse externamente fue nombrado e integrado a rigurosas disciplinas. 
De este modo, constituyeron las asignaturas del currículum: matemáticas, lengua, literatura, zoología, botánica y anatomía (estas tres últimas fueron luego absorbidas por la biología), geografía, historia, física, química, filosofía, artes plásticas, música y educación física. Irremediablemente las últimas tres asignaturas, se alinearon al disciplinamiento que exigía la incorporación de una cultura ilustrada y domesticada. Finalmente, el curriculum quedó preso de esta diferenciación y atomización en saberes fragmentados.

En este marco curricular los métodos han privilegiado el valor del ejercicio en su doble función: aprendizaje y castigo. Los premios, castigos, privilegios y recompensas se constituyen en poderosas herramientas de este proceso de disciplinamiento y normalización. De este modo, la disciplina nos va conduciendo por el camino de encierro, del repliegue del ser, donde la monotonía poco a poco acabará sepultando los instintos que ya hemos abordado y que constituyen la base para el despliegue de la vida. La apuesta de nuestro trabajo desde la perspectiva de la educación biocéntrica se focaliza en recuperar el conocimiento centrado en la vida, superando el disciplinamiento normativo, basado en la represión y el control que ha provocado la perspectiva antropocéntrica de la educación.

\subsection{Del paradigma antropocéntrico a la perspectiva biocéntrica de la educación}

\subsubsection{De lo antropocéntrico a lo biocéntrico}

Nos encontramos en un tránsito gradual pero certero del paradigma antropocéntrico hacia la perspectiva biocéntrica. El refuerzo y ascenso del patriarcado como sistema vincular preponderante ejerció una profunda influencia acentuando el autoritarismo sobre los modos de vinculación humana y fragmentando los vínculos. A este estado, Naranjo (2010b), lo denomina: ego o mente patriarcal (pág. 24); un estado de insensibilidad, voracidad, violencia, 
dominio, sumisión, competencia y dependencia compulsiva. Así, llegamos a adultos desprovistos de este hilo fundamental para vivir el encuentro y el contacto con un mismo y con el otro; los vínculos actuales se encuentran centrados en la competencia desmedida. La educación patriarcal en la que nos encontramos inmersos se ha dedicado fuertemente a la transmisión de información, según Naranjo (2010c): olvidando que el proceso educativo es a la vez un proceso emocional (pág. 57).

La crisis de nuestro tiempo se centra en privilegiar el conocimiento racional y el dominio intelectual-científico-académico; en palabras de Naranjo (2009): "un saber hacer, en detrimento del ser, de sus emociones, sus deseos, sus necesidades" (pág. 59). En este contexto los aspectos sensibles se relegaron y lo que el hombre siente perdió valor.

Desde una perspectiva biocéntrica, que pone la vida en el centro los autores de diferentes épocas como Muir (1971a); Leopold (1949a); Toro (2005a); Cavalcante y Wagner (2015); y Cavalcante, Wagner, Diógenes, Arraes y Regina (2004): han enfatizado la cognición como un proceso vital que incluye el pensamiento, la percepción, la emoción y la acción. Se trata de una conexión profunda con el sí mismo, los otros y el cosmos.

Se busca atender a el vínculo afectivo, o como refiere Naranjo (2010d): el espíritu lúdico (pág. 15); como principal lazo de toda relación y de la trama vincular que nos constituye. En este sentido, la educación debe orientarse al rescate de los instintos habilitando el despertar del deseo, su expresión, realización y elaboración del placer de manera saludable. Necesitamos restablecer la armonía entre las necesidades biológicas fundamentales y las organizaciones humanas que hemos creado. Si somos capaces de permitir la expresión plena del ser, el núcleo de la vida permanecerá inalterable y los acuerdos que podamos establecer para vivir juntos, serán como refiere el autor Toro (2005b): inevitable consecuencia de dicha rehabilitación existencial (pág. $56)$. 


\subsubsection{El principio biocéntrico}

El principio biocéntrico tiene sólidas raíces teóricas que se remontan a los comienzos de siglo XX desde el ámbito de la ecología; tanto Leopold (1949b); como Muir (1971b); y posteriormente, Naess y Sessions (1995): sostuvieron la importancia de que el ser humano debía comprenderse y comportarse como parte de la naturaleza.

El ambientalista, Leopold (1949c), citado por Rozzi (1997), escribió:

(...) la primera ética trató con la relación entre individuos (...), más tarde incorporó la relación entre los individuos y la sociedad (...); actualmente, no existe todavía una ética que trate de la relación entre el hombre y la tierra, los animales, y las plantas que crecen en ella (...). La extensión de la ética a este tercer elemento en el ambiente humano es una posibilidad evolutiva y una necesidad ecológica (pág. 82).

En concordancia con estos postulados, la educación biocéntrica encuentra su pilar fundamental en el desarrollo del principio biocéntrico. Formulado en el año 1970 por Toro; el mismo constituye una innovadora perspectiva para las ciencias humanas. En las mismas líneas, Toro (2005c), expresa:

Ha llegado la hora de dar a la educación un abordaje orientado hacia la supervivencia y el restablecimiento de las funciones originarias de la vida. A partir del Principio Biocéntrico, la educación deberá cultivar las funciones que permiten la evolución afectiva de los seres humanos (pág. 149).

Desde este principio, el cuidado de la vida constituye el hilo conductor de cualquier práctica, metodología y acción que se lleve a cabo. Esto es lo que el principio biocéntrico articula como el eje rector del quehacer humano y de toda práctica educativa. Toro consideró que el principio biocéntrico más allá de una forma de educación constituye una perspectiva de vida. La misma, se distancia de las concepciones antropocéntricas vigentes en nuestra sociedad occidental, potenciadoras de la fragmentación actual a nivel social, cultural, 
económico, de la propia persona. En palabras de Toro (2005d): "el Principio Biocéntrico sitúa el respeto por la vida como centro y punto de partida de todas las disciplinas y comportamientos humanos; restablece la noción de la sacralidad de la vida" (pág. 75).

Este principio propone la estimulación de los potenciales genéticos o inconsciente vital de las personas; una especie de psiquismo celular 0 inteligencia que poseen las células, órganos y tejidos del cuerpo. Esta inteligencia celular-orgánica es la que permite tanto la salud física y emocional por la coordinación, equilibrio y regulación de la energía vital.

Esto se produce al incluir en las metodologías ejercicios vivenciales en los que se estimula la renovación a nivel orgánico; los mismos activan potenciales genéticos de reparación celular y de regulación del organismo. El principio biocéntrico, impulsa la reeducación afectiva y el desarrollo de pautas internas de cada persona para vivir, porque promueve que la identidad particular de cada persona se potencie.

Esta perspectiva, se enfoca en potenciar las capacidades de las personas para desarrollar su parte sana; apunta al desarrollo expresivo y la creatividad; impulsa a la persona a recobrar su poder personal buscando la superación de sus dificultades y autonomía en sus decisiones. En síntesis, estimula a que las personas reconozcan sus necesidades y se conecten con sus deseos.

\subsection{El desarrollo de la educación biocéntrica como metodología de aprendizaje}

\subsubsection{Antecedentes}

El pedagogo y psicólogo chileno Rolando Toro Araneda, es uno de sus principales fundadores. En los distintos lugares donde desarrolló su práctica como educador (Talcahuano, Valparaíso, Pocuro y Santiago) encontró que en la educación tradicional existía una carencia fundamental, el vínculo con la 
vida. Durante sus años como maestro se dedicó a vincular especialmente a los niños con la naturaleza, integrando la afectividad y el disfrute de la vida para aprender a leer, escribir y desarrollar los temas que después seguirían trabajando en las aulas con la expresión artística, especialmente en pintura. La concepción pedagógica de Toro, estaba centrada en formas de aprendizaje vivencial; partiendo de la afectividad, se trataba de integrar la inteligencia con el respeto mutuo y el goce de vivir. Asimismo, dentro del marco pedagógico propuesto, no se excluían las materias de carácter intelectual.

El desarrollo de la enseñanza experimental indujo a Toro a crear el Laboratorio de Psicología en la Escuela de Educación de la Universidad de Concepción. Los desarrollos que realizó a nivel de la educación fueron llevados a la práctica en el año 1965, en el Hospital Psiquiátrico de Santiago donde realizó sus primeras investigaciones con música y danza; reconociendo que ciertas músicas generaban distintos estados emocionales y diferentes respuestas de los internos del hospital. En relación a ello, Toro (2005e), expresó al respecto:

Mi abordaje consistía en incluir la actividad corporal y estimular las emociones a través de la danza y el encuentro humano. Inicié entonces, sesiones de danza con enfermos internados, con el objeto de inducir armonía y tranquilidad en ellos. Propuse danzas armoniosas y lentas con ojos cerrados, y también danzas euforizantes a partir de ritmos alegres que estimulaban la motricidad. Se producían cambios a diferentes niveles: fisiológico, conductual y de adaptación al entorno (pág. 96).

\subsubsection{Caracterización general}

La Educación Biocéntrica se sustenta en el principio biocéntrico desarrollado anteriormente; propone el aprendizaje de nuevas formas de convivencia no competitivas, sino empáticas y considera que la formación intelectual si bien es importante, pierde su sentido, conduce a la violencia y enfermedad si no se realiza en integración afectiva con el orden natural de la 
vida. Esto implica necesariamente el reconocimiento de ser parte de un orden mayor que incluye a la naturaleza, la ecología y la biología.

La metodología de la educación biocéntrica, centrada en la integración corporal-cenestésica, permite según Toro (2005f): "que lo vivenciado en las sesiones de trabajo sea incorporado a actitudes y comportamientos con resultados concretos y eficaces a nivel biológico, fisiológico y psicológico" (pág. 8). Sumando los valiosos aportes brindados por el campo de la psiconeuro-inmuno-endocrinología, estas evidencian el intrincado vínculo entre el sistema nervioso, el sistema inmune y el endócrino. Tanto la mente como las emociones según como mencionan diferentes autores como Sigman y Lipina (2012); Bonet (2013); y Manes (2013): afectan el funcionamiento y la salud de las personas.

La metodología de la educación biocéntrica ejerce influencia sobre esta articulación al implementar técnicas vivenciales, dialógicas, reflexivas que articulan e integran el cuerpo, las emociones y la reflexividad. Las técnicas instrumentadas ejercen influencia sobre la funcionalidad del cerebro, el cuerpo y las emociones. Los ejercicios vivenciales ejercen directa influencia sobre el sistema integrador-adaptativo límbico-hipotalámico el cual se vincula directamente con la expresión de los instintos, de las emociones y afectos. Asimismo, los distintos ejercicios son activadores o inhibidores de los sistemas simpático (vinculado con la actividad y la vigilancia) y parasimpático (relacionado con el reposo y el sueño) con la finalidad de estabilizar el equilibrio neurovegetativo.

\subsubsection{El movimiento y la música como medio para el aprendizaje}

Los desarrollos teóricos clásicos en torno al aprendizaje el autor Piaget (2018): como también los aportes más recientes de las neurociencias por parte de Lacoboni (2011); Ramachandran (2012); y Rizzolatti y Sinigaglia (2006): señalan la estrecha relación entre aprendizaje y desarrollo motor. El 
aprendizaje es movimiento e integración, por lo que podrá advertir el lector las graves consecuencias de una educación normativo-disciplinaria para el aprendizaje y desarrollo humano. Desde la perspectiva de la educación biocéntrica el movimiento es primordial para aprender.

En la educación tradicional se transmite un modo de vivir escindido del cuerpo, el movimiento está prohibido, el cuerpo está enyesado; el contacto y el deseo están imposibilitados, cuando paradójicamente la vida se expresa en el cuerpo. Es a través del movimiento como se conoce el mundo. La física cuántica sostiene que el movimiento es una propiedad de la naturaleza. De este modo el mundo que percibimos denso y material no es estático, sino rítmico.

En este sentido, el movimiento y el aprendizaje tienen directa y estrecha vinculación con la danza. No son pocos los teóricos que utilizan este término en su lenguaje científico, Bohm (1988); y Pauli (1948): hacen referencia a la danza de protones, Senge (1992): por su parte refiere a la danza del cambio.

En tanto el aprendizaje es movimiento, si no nos movemos no aprendemos; en este sentido, todo aprendizaje generado por el movimiento corporal se incorpora eficazmente a actitudes y comportamientos de las personas. Por ello, mover el cuerpo no es una metáfora, es un ejercicio coherente con este proceso. Dicho movimiento no se encuentra restringido a algunas partes de nuestro cuerpo, hablar, mover las manos o cambiar la dirección de nuestra vista, sino que compromete toda nuestra corporalidad.

Los aportes científicos antes citados provenientes de la psicología, biología, física y neurociencias cobran valor en la metodología que instrumenta la educación biocéntrica; en la cual, durante los ejercicios, la combinación entre la música, el movimiento y las consignas conduce a vivencias integrativas. Toro encontró en la música, la capacidad de estimular vivencias intensas. La música, utilizada como elemento central en el dispositivo pedagógico de la educación biocéntrica, fue cuidadosamente utilizada por 
Toro (2005g): "para inducir (deflagrar) distintos estados emocionales, pues existe una coherencia entre ciertos patrones de sonidos y las emociones que los mismos despiertan en las personas al escucharlos" (pág. 69).

Diferentes autores desde el campo de la psicología, especialmente la musicoterapia, investigaron su significado emocional, el poder y valor de la música y los beneficiosos efectos sobre el cuerpo, entre ellos Alfred Tomatis, Don Campbell, Michel Imberty. Asimismo, desde el campo de la neurociencia, Pert (1999), contribuye a profundizar el valor y la importancia de la música; según esta autora, la música: “...es una forma de comunicamos entre nosotros, al igual que las emociones, ya que como ellas posee una cualidad emocional. Todos los sonidos que oímos afectan a nuestro organismo" (pág. 159).

\subsubsection{La vivencia como fuente de conocimiento en la pedagogía biocéntrica}

La vivencia es percepción fenoménica pura, situaciones en sí, es el instante, la expresión pura de la emoción, sin interpretación (reflexión) de quién la vive. Es sensación y sentimiento de aquello que pasa por un registro que trasciende lo reflexivo-racional y lleva a la persona a conocerse, y aprehender como dice Toro (2005h): el mundo mediante sensaciones propias (pág. 25). Certeza de lo vivido que involucra su reconocimiento en lo que para el autor Yontef (2002), constituye: el acto de darse cuenta y hacerse cargo (pág. 15). Esta certeza se produce según Varela (1990): desde la conciencia abierta y presencia plena (pág. 32). En dicho movimiento, se ponen en juego el espacio, el tiempo y la consciencia del instante presente. La vivencia se inscribe en el inconsciente de las personas y es transformadora del proceso existencial porque implica un compromiso cenestésico. Toro (2005i), afirma que en "el compromiso cenestésico donde no intervienen la razón y la voluntad y lo vivido que escapa de la explicación racional se incorpora en el cuerpo" 
(pág. 94).

Lo particular de este tipo de metodología es que la articulación de movimiento-música-vivencia mediante ejercicios y juegos, constituyen ecofactores, (factores ambientales) que ejercen influencia sobre la función integradora-adaptativa-límbico-hipotalámica redundando esto en la reeducación afectiva; ya que se logra con esta integración, como afirma el autor Toro (2005j): reeditar lo aprendido a nivel psíquico y biológico (pág. 44).

\section{Conclusiones}

El recorrido realizado hasta aquí, nos permitió revisar la perspectiva disciplinaria de la educación que enyesa las necesidades básicas-instintivas del ser humano y con ello su proceso mismo de aprendizaje. La falta de motivación, el desgano y el aburrimiento que hoy denuncian tanto docentes como alumnos en nuestras instituciones educativas encuentra directa relación con la desconexión con la vida, provocando un desencantamiento del mundo. Girando este sentido, como hemos desarrollado en este trabajo, la perspectiva biocéntrica de la educación pone especial atención a la conexión del ser consigo mismo, con el otro y con todo el cosmos que lo rodea. Esto implica reconocer el valor de todos los seres vivos, como una hebra fundamental en el tejido social, cultural, ecológico, político y educativo.

Este reconocimiento nos devuelve autonomía, potencia, poder y conexión con la fuerza creativa y creadora del hombre en vinculación con la capacidad que mencionan los autores Maturana y Varela (1984): "de auto-ecoorganización humana, dependiente e independiente a la vez de sí mismo y del entorno en un proceso de acoplamiento estructural" (pág. 79).

Este trabajo se propuso revalorizar lo instintivo originario que vincula cognición y vida. Desde la perspectiva que desarrollamos aquí, proponemos considerar a la vida como eje organizador del curriculum, y no las disciplinas, recuperando el sabor del saber y la pasión por enseñar y aprender. Esto 
permite según Toro (2005k): "religar las fracturas impuestas culturalmente por la educación tradicional; desactivar la maquinaria de la modernidad y activar el laboratorio interior del ser humano" (pág. 19); para que la persona reconozca sus necesidades y se conecte con sus deseos.

En este sentido no se trata de desestimar los saberes particulares en los que hemos profundizado en la modernidad: biología, física, matemática, lingüística, etc., sino de volver a religar esos saberes con la vida misma. Se trata de un reencantamiento del mundo que tome distancia de los indicadores de eficacia, eficiencia y productividad propios de un modelo fragmentario del ser humano y su comunidad, para recuperar el sentido más profundo del ser que requiere reconocerse uno con otros, en la configuración del nosotros.

La pedagogía biocéntrica integra lo natural instintivo con el movimiento (E-Motion) ineludible de la vida, donde emergemos como otro diferente pero no separado (lenguaje-colaboración) para juntos co-evolucionar. La metodología biocéntrica desmilitariza y desmoraliza los cuerpos acorazados por la represión. Esta pedagogía posibilita una reeducación afectiva-efectiva de las personas abriendo a la posibilidad de vinculación con el semejante mediante la mirada que reconoce, califica y hospeda a la otredad.

\section{Referencias}

Althusser, L. (1970). Aparatos ideológicos del estado. Buenos Aires, Argentina: Nueva Visión.

Bohm, D. (1998). La totalidad y el orden implicado. Barcelona, España: Editorial Kairós.

Bonet, J. (2013). Pine. Buenos Aires, Argentina: Ediciones B.

Canguilhem, G. (1990a,b). Normal e o Patológico. Rio de Janeiro, Brasil: Forense Universitária.

Carpintero, E. (2015a,b). El erotismo y su sombra. El amor como potencia de ser. Buenos Aires, Argentina: Editorial Topia. 
Cavalcante, R., \& Wagner, C. (Col.). (2015). Educação Biocéntrica: ciência, arte, mística, amor e transformação. Fortaleza, Ceará, Brasil: Edições $\mathrm{CDH}$.

Cavalcante, R., Wagner, C., Diógenes, F., Arraes, C., \& Regina, C. (2004). Educación biocéntrica. Un movimiento de construcción dialógica. Fortaleza, Ceará, Brasil: Edições CDH.

Comte, A. (1830). The Positive Philosophy. Brooklyn, Nueva York, EE. UU.: AMS Press, Inc. Edición en castellano: La filosofía positiva. México: Porrúa, 1979.

Durkheim, E. (1985). Las reglas del método sociológico. Chile: Editorial Fondo de Cultura Económica.

Foster, J. (2010). The Wonder of Being: Awakening to an Intimacy Beyond Words. Oakland, EE. UU.: New Harbinger Publications.

Foucault, M. (1975a,b,c,d,e). Vigilar y castigar. Nacimiento de la prisión. Buenos Aires, Argentina: Siglo XXI Editores.

Lacoboni, M. (2011). Las neuronas espejo. Barcelona, España: Katz Editores.

Leopold, A. (1949a,b,c). A sand county almanac, and sketches here and there. Oxford, England: Oxford University Press.

López, C. (2019). Practica Educativa en la Educación Primaria desde la Perspectiva de la Pedagogía del Amor. Revista Scientific, 4(11), 280294. Recuperado de: https://doi.org/10.29394/Scientific.issn.25422987.2019.4.11.14.280-294

Manes, F. (2013). La creatividad como clave del futuro. En sección de Opinión, pág. 19, publicada el 5 de agosto. Buenos Aires, Argentina: Diario La Nación.

Maturana, H., \& Varela, F. (1984). El árbol del conocimiento: Las bases biológicas del entendimiento humano. Buenos Aires, Argentina: Editorial Lumen. 
Muir, J. (1971a,b). My First Summer in the Sierra. Boston, EE. UU: Houghton Mifflin Harcourt.

Naess, A., \& Sessions, G. (1995). "Platform Principles of the Deep Ecology Movement". In Drengson, A. and Inoue, Y. Eds. The Deep Ecology Movement: An Introductory Anthology. Berkely, C.A.: North Atlantic Books, pp. 49-53.

Naranjo, C. (2009). Sanar la civilización. Barcelona, España: La llave.

Naranjo, C. (2010a,b,c,d). La mente patriarcal. Barcelona, España: RBA Integral.

Pauli, W. (1948). Meson theory of nuclear forces. New York, United States: Interscience Publishers, Inc.

Pert, C. (1999). Molecules Of Emotion: The Science Between Mind-Body Medicine. Simon and Schuster. Maracaibo, Venezuela: Cesa - Faces - Universidad del Zulia.

Piaget, J. (2018). Seis estudios de Psicología. Argentina: Siglo XXI Editores. Ramachandran, V. (2012). Lo que el cerebro nos dice. España: Ediciones Paidós.

Reich, W. (1927a,b). La función del orgasmo. El descubrimiento del orgón Problemas económico-sexuales de la energía biológica. España: Ediciones Paidós.

Rizzolatti, G., \& Sinigaglia, C. (2006). Las neuronas espejo. Barcelona, España: Ediciones Paidós.

Rozzi, R. (1997). Hacia una superación de la dicotomía biocentrismoantropocentrismo. Ambiente y Desarrollo, 13(3), 80-89, ISSN: 07161476.

Senge, P. (1992). La quinta disciplina. El arte y la práctica de la organización abierta al aprendizaje. Buenos Aires, Argentina: Ediciones Granica.

Sigman, M., \& Lipina, S. (2012). La pizarra de Babel. Puentes entre 
Neurociencia, Psicología y Educación. Buenos Aires, Argentina: Libros del Zorzal.

Strauss, A., \& Corbin, J. (1994). Grounded Theory Methodology: An Overview. In N. K. Denzin, \& Y. S. Lincoln (Eds.), Handbook of Qualitative Research (Charpter 17, pp. 273-285). Thousand Oaks, C.A.: SAGE.

Toro, R. (2005a,b,c,d,e,f,g,h,i,j,k). Biodanza. Chile: Ed. Cuarto Propio.

Varela, F. (1990). El Fenómeno de la Vida. Santiago de Chile: Dolmen Editorial.

Yontef, G. (2002). Proceso y diálogo en Psicoterapia Gestáltica. Santiago de Chile: Cuatro Vientos. 


\section{Claudia Liliana Perlo Pachega \\ e-mail: perlo@irice-conicet.gov.ar}

Nacida en Rosario, Argentina. Doctora en Educación;

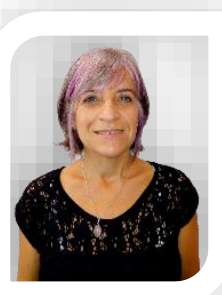
Investigadora del Consejo Nacional de Investigaciones Científicas y Técnicas (Conicet) en el Instituto Rosario de Investigaciones en Ciencias de la Educación (IRICE); donde coordina el Área de Aprendizaje y Desarrollo Organizacional. Soy Profesora Didacta de Biodanza por la International Biocentric Federation (IBF). Me desempeño como docente de postgrado en la Universidad Nacional de Rosario y la Universidad del Centro Latinoamericano de Argentina. Autora de libros y numerosos artículos publicados en revistas nacionales e internacionales; desarrollo mi tarea, brindando conferencias y asesoramientos en las organizaciones, con un fuerte compromiso de vinculación entre la ciencia, el conocimiento y la sociedad.

El contenido de este manuscrito se difunde bajo una Licencia de Creative Commons ReconocimientoNoComercial-Compartirlgual 4.0 Internacional 